1 AUDIENCE BEHAVIOR IN CHINA AND THE U.S.

\title{
A Network Analytic Approach to Audience Behavior and Market Structure: The Case of China and the U.S.
}

\begin{abstract}
This study adopts a network analytic approach to understand media audiences in relation to media markets, bridging the literature on audience behavior and media economics. Using audience data in the Chinese and U.S. markets, we apply multi-level measures to compare audience fragmentation patterns, a key indicator of market structure, across television channels. Drawing on McQuail's four-stage fragmentation model, we find the Chinese television market exhibits the Core-Peripheral model where a few channels dominate the marketplace and the rest are viewed by niche segments of the audience. In contrast, the U.S. market represents the Pluralism model with extremely high levels of audience duplication across channels, suggesting overlapping patterns of exposure throughout the market rather than isolated segments.
\end{abstract}

Keywords: audience fragmentation, network analysis, audience behavior, media economics, Chinese television 


\section{AUDIENCE BEHAVIOR IN CHINA AND THE U.S.}

Media audiences have been a key interest area for both audience researchers and media economists. These two fields are related in important ways, yet work in one area seldom has informed the other (Napoli, 2003). Audience research has mainly focused on describing and explaining the complexities of audience behavior (e.g. McQuail, 1997;

Webster, 2005), as well as explicating motivations and meanings of such behaviors (e.g. Ang, 1991). Research in this field frequently takes on micro-level, preference-based frameworks such as the uses and gratifications theory, which attributes media choice to purposeful individual users motivated by their expectation of need gratification (Katz, Blumler, \& Gurevitch, 1974). As such, this body of research tends to overlook media audiences as an economic product with unique characteristics and significant points of interaction with media markets (Napoli, 2003).

In contrast, media economics traditionally concentrates on the influence of market structure, often manifested in market concentration, on the performances of media companies or various media industries (e.g. Owen \& Wildman, 1992; Ramstad, 1997; Wirth \& Block, 1995; Young, 2000) to the omission of the complexities of audiences in the functioning of these industries (Napoli, 2003). This body of research often relies on simplifying assumptions about audience behavior, and consequently lacks reasonable approximation of the reality of media audiences (Napoli, 2003; Owen \& Wildman, 1992).

Exceptions exist where scholars approached audience behavior from the perspective of their interaction with structural factors of the media. Webster (2011) proposed a theoretical integration of the micro-level actions of media users and the macro-level effects of media structure in audience research. He argued that the interaction between audience agency and media structure results in the "duality of 


\section{AUDIENCE BEHAVIOR IN CHINA AND THE U.S.}

structure" (Giddens, 1984) — a recursive process in which media organizations as resource providers and media users as agents mutually constitute and influence each other.

This study adopts a network analytic approach to integrate market structure and aggregate agency in the study of media audiences. In doing so, we also aim to bring audience researchers and media economists into the same conversation. The empirical examples of China and the United States, the world's two largest and most complex television markets, are used to demonstrate the value of network analysis in bridging these frameworks. The two markets are conceptualized as networks with television channels as nodes and audience flow patterns as links among the nodes. We adopt network measures to gauge audience fragmentation and concentration in each market. These measures allow us to compare audience behavior patterns, manifestations of audience agency, as well as macro-level characteristics of market structure in the two countries. This network perspective helps us represent the dynamics between audience behavior, media organizations and market structure.

In this study, we model audience fragmentation with analytical network measures at both subgroup and network levels using People Meter data from China and the United States. We find that network properties - density, centralization, and clique membership — embody different patterns of audience fragmentation in the two complex markets. The findings suggest that while China has evolved into a Core-Periphery model showing alternative options outside the structure of the central core, the United States can best be characterized by a Pluralism model with a high degree of overall market 


\section{AUDIENCE BEHAVIOR IN CHINA AND THE U.S.}

fragmentation (Kim, 2010; McQuail, 1997). Finally, we discuss the implications of such differences for the two markets.

\section{Literature Review}

In this section, we first explain how audience researchers and media economists conceptualize fragmentation in alternative ways. We then propose integrating these two approaches using network analysis, and introduce McQuail's four-stage model of fragmentation as our analytical framework. Lastly, we explain the differences in the media markets in China and the U.S. to motivate our hypotheses.

\section{Audience Fragmentation in Changing Media Environments}

We conceptualize audience fragmentation as both a state - the current extent to which audiences distribute their attention across media outlets or content options as they

grow in number - and a process in which the distribution progresses towards polarization, signaled by a complete lack of overlap among audiences. Audience fragmentation has been a focus for both audience researchers and media economists, albeit with different approaches (Anderson, 2006; Chaffee \& Metzger, 2001; Webster, 2005; Young, 2000). Audience researchers tend to place audience autonomy at the center of the study of audience fragmentation. The basic assumption is that purposeful and rational media use results from an individual's psychological predispositions such as needs and preferences as the primary cause of behavior (Webster, 2011). Some contend that in an increasingly abundant and selective environment people are now better positioned to consistently choose their favorites and avoid anything they find disagreeable or intrusive. Consequently, audiences may highly concentrate on a particular type of content or media and become specialized in their patterns of consumption (Chaffee \& Metzger, 2001; Graf 


\section{AUDIENCE BEHAVIOR IN CHINA AND THE U.S.}

\& Aday, 2008; Stroud, 2010; Webster, 2005). This prospect has led researchers to lament the potential detrimental social consequences of audience polarization (Sunstein, 2007; Turow, 1997). Others focus on how individual media use can be more or less distributed across available options. They may form "media repertoires," subsets of available media that individuals consume frequently, as a "coping strategy" for finding favorable content in an increasingly complex media environment (e.g., Ferguson \& Perse, 1993; Yuan \& Webster, 2006).

In contrast, economists have developed various measures to assess audience fragmentation - and its inverse, concentration - as characteristics of market structure and to model how different structural conditions affect media programming and market performance (Neuman, 1991; Owen \& Wildman, 1992; Webster, 2005; Wirth \& Block, 1995; Yim, 2003; Young, 2000). The industry tracks how total audience attention is distributed across channels, which channel gets the most viewers at a particular time point, or how accumulated audience attention for each channel is either polarized or evenly distributed (Young, 2000). A popular way to represent audience fragmentation in this form is to show the distribution as a long tail (Anderson, 2006), which is often used to depict unbalanced patterns of use in which a few media outlets or products dominate the marketplace (Neuman, 1991). As such, they summarize the level of fragmentation in a given market at a point in time. However, such distributions only enable us to see what is popular and what is not, but provide little insight on how consumers choose to spread their attention across these options.

While early media economists posited market structure as "exogenous" and cared little about how media users behave or how company strategies relate to the workings of 


\section{AUDIENCE BEHAVIOR IN CHINA AND THE U.S.}

the audience-oriented market in general (Ramstad, 1997), a better theoretical foundation for the workings of the media marketplace needs to take into consideration the intricate relationship between industry structure and audiences (Wirth \& Block, 1995; Young 2000). The integrated theoretical framework of "duality of structure" (Webster, 2011) for understanding fragmentation unites the different approaches to audience behavior and market structure outlined above. In the following section, we propose a network analytic approach, which enables us to empirically examine market structures in terms of audience behavior.

\section{Network Approach to Audience Fragmentation}

With the audience at the center of their models, conventional audience and industry approaches to fragmentation often fail to address the mutual influence of agency and structure in the marketplace. In order to better understand how audience preferences are structured and how their resulting program choices influence the market, researchers should account for the emergence of media consumption patterns by describing market structure in relation to audience behavior, as well as the dynamic relations between media players (Webster, 2011; Yuan \& Ksiazek, 2011).

This study adopts network analysis metrics to study audiences in the media marketplace. That marketplace is conceptualized as a network, comprised of major media players (e.g., TV channels) as nodes. The links that connect these nodes are defined by the shared audience, or duplication, between media outlets (For detailed treatments of this network conceptualization see: Ksiazek, 2011; Webster \& Ksiazek, 2012; Yuan \& Ksiazek, 2011). 


\section{AUDIENCE BEHAVIOR IN CHINA AND THE U.S.}

Audience duplication belongs to a long tradition in audience analysis that measures the extent to which audiences for multiple media products (e.g., TV programs, websites, magazines, etc.) overlap (e.g., Barwise \& Ehrenberg, 1988; Ksiazek, 2011; Webster, 2006). The metric indicates the following: Of the total audience, how many use a particular set of media outlets?

In this study, we apply network concepts to gauge fragmented audience consumption patterns. We model and summarize these properties at network and subgroup levels (Kim, 2010; Monge \& Contrator, 2003). While audience flow patterns reflect aggregate audience agency, network properties represent characteristics of market structure. This way, the network approach is illustrative of the mutually constitutive nature of media structure and audience agency.

\section{Patterns and Process of Audience Fragmentation}

McQuail (1997) proposed a descriptive model that registered four possible patterns along the process of audience fragmentation: the Unitary, the Pluralism, the Core-Periphery, and the Breakup pattern. The Unitary pattern exists at a time when people share similar patterns of media consumption provided by a very limited number of media outlets that are universally available. For instance, this would be descriptive of the early American TV industry when three major broadcast networks dominated the marketplace, or the highly centralized communist Chinese TV system before the growth of ad-supported television. As channels proliferate and options become more diverse, audience fragmentation advances into what McQuail calls the Pluralism and CorePeriphery patterns. The former describes a market with increased fragmentation, but still a great deal of overlap, whereas the latter shows a central core (i.e., universally popular 


\section{AUDIENCE BEHAVIOR IN CHINA AND THE U.S.}

channels) along with the emergence of smaller subgroups of channels outside of that core. Here, most viewers watch the "core" channels to a certain degree, but otherwise they display diverse viewing patterns. Finally, the Breakup pattern represents the most extreme case of audience fragmentation, where the central core dissolves and the market consists of non-overlapping subgroups. This final stage of audience fragmentation would be indicative of audience polarization (Webster, 2005).

Arranging the four patterns along a unidirectional temporal line, McQuail's fragmentation model assumes strict linearity in the progression of these patterns. Such an assumption, we argue, does not necessarily or adequately reflect the complexity in the development of fragmentation in the real world. Although McQuail (1997) acknowledged that the potential formation of the four patterns was premised on socioeconomic as well as technological factors in different markets, there has been little serious theorization based on empirical evidence to relate the patterns to media environments of differing political economic characteristics. After all, audiences are both a product of social context (i.e., shared cultural interests, understandings, and information needs) and a response to the structure of media provision, the general pattern of what the media provide in a given society (McQuail, 1997). The makeup of a given (national) media system (e.g., number, reach, and type of media available) is shaped by the specific characteristics of different media outlets as well as audience preferences and choices cultivated in the system. McQuail's descriptive model offers an analytical point of departure to explore the integration of aggregate audience agency and market structure.

\section{The Political Economies of Chinese and U.S Television}




\section{AUDIENCE BEHAVIOR IN CHINA AND THE U.S.}

In this section, we first briefly introduce the Chinese and U.S. media markets and then offer hypotheses for audience fragmentation at both network and subgroup levels in each country. Our introduction to the two markets mainly focuses on their distinct structural characteristics relevant to the current study.

Chinese television used to be a communist communication system established on a central-local hierarchy and along administrative boundaries (Chan, 2003). In this system, all TV stations, owned by the governments at either the central, provincial, or metropolitan levels, had long relied on government subsidies. However, as a result of the country's market-oriented economic reforms in the past few decades, a burgeoning advertising industry has become the driving force for the development of the media markets at various levels.

Drawing the world's largest audience, the national television market bears important sociopolitical and economic significance in China. There are two major types of television in China's national market. First and foremost is China Central Television (CCTV), a former national monopoly under the auspices of the central government. CCTV owns and operates 15 national channels. Second, 31 provincial television services (one for each of the 31 provinces in China) were made available to the national audience through satellite-fed commercial cable systems across the country in the early 2000s (Chan, 2003). These locally originated yet nationally available channels are both serious political organs serving the provincial governments and lucrative economic vehicles that bring in national advertising revenues. Besides these major players, there are a few channels operated by regional and international media corporations in the national market. 
10 AUDIENCE BEHAVIOR IN CHINA AND THE U.S.

CCTV channels, by default and by design, remain the dominating force in the national market, despite the increasing market competition. CCTV continues to enjoy government-enforced privileges such as access to exclusive news information and rich resources in terms of capital and talent. CCTV's evening news and current affairs programs, for instance, are required to be relayed by all provincial channels across the nation during prime time. In light of CCTV's political advantage, provincial channels often employ the lowest-common-denominator approach by focusing on alternative entertainment programming. Such strategies have earned some stations national fame and significantly expanded their audience bases (Chan, 2003).

This state-market dynamic is fundamental to understanding Chinese television (Zhao, 1998). The state strives to rein the force of media marketization, while exploiting its potentials, within its central-local hierarchy and political boundaries. The market, coupled with serendipitous technological advancement, on the other hand, often presents new challenges for the state to contain within the existing parameters (Chan, 2003). The intricate interplay between political concerns and market mechanisms has led to a complex trajectory in China's TV market (see Zhao, 1998).

The U.S. media marketplace offers an interesting contrast to the Chinese system. The American TV industry developed in a free-market, capitalist system. With the exception of subsidies for PBS, television channels in the U.S. are typically privately owned and operated. The government's laissez-faire approach is rooted in upholding the marketplace of ideas, where media diversity is celebrated and government intervention is fairly limited. Recent legislation (e.g., the Telecommunications Act of 1996) eased 


\section{AUDIENCE BEHAVIOR IN CHINA AND THE U.S.}

ownership restrictions in the industry and has facilitated the current oligopolistic structure.

Interestingly, the recent concentration in ownership has been coupled with more diverse programming. That is, while ownership has been consolidated, the small group of controlling companies has actually expanded the range of content available — primarily in response to demonstrated demand for specialized programming. For example, $21^{\text {st }}$ Century Fox owns FOX and MyNetworkTV broadcast networks, dozens of local broadcast affiliates across the country, and several cable channels such as FOX News, National Geographic, Fox Sports 1, etc. Many other large media conglomerates have similar property structures (Arsenault \& Castells, 2008). The result is an increasingly diverse and specialized array of channel and program options for the American TV viewer.

The example above offers a microcosm of the broader structure of the American TV marketplace. There are three basic types of television channels in the U.S. Broadcast networks are nationally available via affiliate stations throughout the country. These include ABC, CBS, NBC, FOX, as well as MyNetworkTV, CW, Telemundo and Univision. Traditionally, the local affiliates of these national networks limit most of their original production to news content and rely on the networks and other syndication agreements to fill out their program schedules. The third type of channel is the cable/satellite network available via service providers that increasingly offer specialized content.

Given the noted differences in the political economies of the two television systems, it is only natural to expect that the two also differ in market structure and 


\section{AUDIENCE BEHAVIOR IN CHINA AND THE U.S.}

patterns of audience behavior. Consequently, they should show distinctive audience fragmentation patterns, which are both affected by and constitutive of current market conditions. We are motivated to see if the current observed TV audiences in the two systems fit any of the speculated patterns in McQuail's fragmentation model. Using a network analytic approach, we test the validity of the model against the empirical specificities of the two markets. This analytical development integrates market structure and aggregate audience agency, and urges a theoretical bridge between audience researchers and media economists.

\section{Research Hypotheses}

Thanks to the available multi-level network measures, we are able to tell a holistic yet nuanced story about the fragmentation patterns for the two markets. Instead of simply indicating the size of the audience of a given outlet relative to the other outlets in that market, the network approach provides a more complete picture by accounting for the exposure patterns of that audience across those other outlets.

The analysis employs measures at both subgroup and network levels. At the network level, we aim to depict the overall degree of audience fragmentation and concentration in the two markets by computing network density and network centralization scores. The former is the ratio between observed ties and total possible ties among channels in the market, where ties are defined by shared audience members. The higher the density score, the more ties there are between channels in the market. In other words, a high density level in the network shows a high general tendency for the audience of one channel to also watch another channel, i.e. a high degree of audience flow (duplication) between channels. Therefore, density is a good indicator of audience 


\section{AUDIENCE BEHAVIOR IN CHINA AND THE U.S.}

fragmentation in the sense that a high network density ratio indicates that we have a great deal of audience overlap across all channels in the network. Please note that it is somewhat counterintuitive that a network of television channels is densely connected (indicated by a high density score) in analytical network terms yet fragmented in theoretical audience research terms.

Similarly, network centralization is an indicator of the degree to which audiences tend to duplicate evenly across the network (fragmentation), or duplicate disproportionately with a small number of media outlets (concentration). Network centralization is a measure of the variability or inequality in the degree scores of all nodes in a given network (Freeman, 1979). In this case, a high centralization score indicates greater concentration, while a low score suggests greater fragmentation. Thus, high density should be coupled with low centralization (both indicating fragmentation), while low density should be paired with high centralization (indicating more concentration).

At the subgroup level, we aimed to gauge more intricate patterns of audience behavior and market structure by examining the number of cliques and clique comembership patterns. A clique is defined as a fully connected subgroup in the network (i.e., a great deal of audience overlap among a subset of channels) (Hanneman \& Riddle, 2005, Ch. 11). The existence of cliques indicates that audiences display loyalty to subsets of channels, as opposed to distributing their attention more widely in the market. Related, clique co-membership identifies channels that belong to multiple cliques. Greater overlap in the co-membership matrix is consistent with higher levels of fragmentation. In other words, this suggests that audience members overlap with more channels in the market and thus spread their viewing among a wider range of options. 


\section{AUDIENCE BEHAVIOR IN CHINA AND THE U.S.}

We posit that the density of the Chinese television network should be comparatively low because its audience flow is affected by the central-local structure, the difference in programming on CCTV and provincial channels, as well as segmented local markets paralleling the national market. ${ }^{1}$ For the same reason, the network centralization score of the Chinese market should be higher than that of the U.S. market. Overall, we expect that the Chinese market will be consistent with the Core-Periphery model.

In contrast, as a commercial media system that is directly responsive to market forces and feedback from audiences, the U.S. market tends to maintain a stable selfregulating balance between supply and demand (McQuail, 1997). Recent research on audience fragmentation in the U.S. finds extremely high levels of audience duplication across channels, suggesting overlapping viewing patterns across diverse options (Webster, 2005; Webster \& Ksiazek, 2012). Therefore, we expect the density of the network to be high. Similarly, the network centralization measures should be low because there is no core in this market that connects other subgroups that are otherwise disconnected. At the subgroup level, the network is more likely to be divided by a few cliques of which members share clique co-memberships. In sum, we expect the United States TV market to be consistent with the Pluralism model.

H1: The network density of the Chinese television market is lower than that of the U.S. market.

H2: The network centralization of the Chinese television market is higher than that of the U.S. market. 


\title{
15 AUDIENCE BEHAVIOR IN CHINA AND THE U.S.
}

\section{H3: The two markets display disparate patterns of audience fragmentation, with the Chinese market reflecting the Core-Periphery pattern and the U.S. market demonstrating the Pluralism pattern.}

\begin{abstract}
Method
The audience data for both the Chinese and U.S. markets come from People Meter panels. People Meters are electronic devices that, when attached to the TV set, automatically record minute-by-minute viewing behavior of all members in the sample households. Such meters are known to produce a much more precise audience viewing record than either diaries or telephone recall techniques, and therefore have become the preferred method for measuring television audiences worldwide (Webster, 2005).

The Chinese panel, owned and operated by CVSC-Sofres Media (CSM), consists of 5,000 television households and 13,155 individuals. The panel, created through a multi-stage probability sampling process, is the world's largest audience measurement endeavor and represents the national audience across China. The data for the U.S. market come from Nielsen's TV/Internet Convergence Panel, which provides single-source respondent-level data on TV and Internet use in 1,020 homes. The panel of 2,771 people primarily consists of former members of Nielsen's National People Meter Panel and Nielsen's National Hispanic Television Index, while the rest were newly recruited. The panel is generally representative of the U.S. population across major demographic categories. CSM and Nielsen, endorsed by the media and advertising industries in their respective markets, provide the "currency" on which TV ratings are based and advertising space is bought and sold in China and the U.S.

This study created two networks consisting of all the major national channels, as nodes, in their respective markets to represent the Chinese and U.S. television systems.
\end{abstract}




\section{AUDIENCE BEHAVIOR IN CHINA AND THE U.S.}

There were a total of 62 channels from the Chinese market and 98 in the U.S. market (Channels with a reach less than $3 \%$ were excluded from the study for insufficient sample size). In other words, the Chinese television market is represented by a network of 62 nodes, and the U.S. by 98 nodes, connected by the audience duplication patterns between these nodes.

Audience duplication between these channels (nodes), measured as the percent of the total audience who watches both channels for one or more consecutive minutes during the months in question, constitutes undirected ties among the channels. The duplication data were aggregated based on the minute-by-minute People Meter data in the two markets. The data for China were excerpts of the panel data from April, 2010, and the data for the U.S. market were from March, 2009. In order to offer a conservative measure of duplication that is not biased by the basic audience size of a given outlet, we use a measure of deviation-from-random duplication (Ksiazek, 2011). In simple terms, this metric accounts for the degree to which the observed duplication between two channels exceeds random chance. In cases where dichotomized data were necessary for the analytical procedures, we used expected duplication as a threshold. That is, if the observed exceeds the expected, a tie is present; if not, a tie is considered absent.

At the network level, we analyzed network density and network centralization for each market. At the subgroup level, we identified the number of cliques and created a clique co-membership matrix. Yuan and Webster (2006) found on average Chinese viewers watch 13 channels regularly. In the U.S., that figure is just slightly higher (Mandese, 2009, July 21). Therefore, we set the threshold for clique size at ten or more channels. The results of these four analyses, described in detail below, provide 


\section{AUDIENCE BEHAVIOR IN CHINA AND THE U.S.}

comparative metrics for evaluating both audience behavior and market structure in China and the U.S. and determine the appropriate pattern of fragmentation to describe each system.

This study utilized UCINET 6.0 for the network analyses (Borgatti, Everett, \& Freeman, 1999). For H1 and H2 we computed the density and centralization scores for both networks. High density suggests widely dispersed audience attention and a great deal of overlap across the channels (fragmentation) and a low score suggests concentration. A high network centralization score, on the other hand, suggests inequality, or a tendency for audiences to disproportionately watch a small number of popular channels. Together, high centralization (paired with low density) indicates market concentration, while low centralization (and high density) suggests market fragmentation. We also conducted a t-test to compare the mean centrality scores between the two networks. These scores are used to compute an overall centralization score (Freeman, 1979; Ksiazek, 2011) and also provide insight into our observed density scores. This procedure provides a significance test to complement our descriptive analyses. For H3, we ran a clique analysis to obtain the number of cliques and a comembership matrix.

\section{Results}

The results suggest that the two markets differ in both the degree and patterns of fragmentation. Consistent with our hypotheses, the Chinese TV market has a much lower network density and relatively high centralization, which signifies a less balanced and more concentrated market. Moreover, the Core-Periphery pattern best describes the Chinese market, while the U.S. market is more akin to the Pluralism pattern. In other 


\section{AUDIENCE BEHAVIOR IN CHINA AND THE U.S.}

words, the Chinese market is characterized by a core of universally popular channels, along with distinct subgroups of channels outside this core. Alternatively, the U.S. market exhibits a much higher degree of overall fragmentation, and thus greater overlap in general across all channels. In this model, the audience members spread their attention widely, but since all of them do so, they end up with many common viewing experiences (see Figure 1).

\section{---Insert Figure 1 about here---}

As suggested above, there is an inverse relationship between density and centralization at the network level. The network density of the Chinese television market is $32 \%$ and the centralization score is $43.77 \%$. In contrast, the density of the U.S. television market is $99 \%$ and the centralization score is $0.30 \%$. The moderately high centralization score for the Chinese market indicates that there seem to be some channels that people disproportionately watch. At the same time, the low density score tells us that only about one-third of all possible ties are present. Thus, most of the channels do not display above-random patterns of overlap. This seems to hint at a Core-Periphery pattern.

As for the U.S. market, the density score indicates that almost all possible ties are present in the market (i.e., audiences duplicate widely across almost all channels at levels that exceed random chance). This, coupled with the extremely low centralization score, suggests that viewers, in the aggregate, exhibit great diversity in their viewing patterns. Moreover, since everyone seems to be rather diverse, we could characterize this market by “diversity in unity," or the Pluralism model (McQuail, 1997).

A t-test of the difference in mean centrality scores between the Chinese $(M=$ $32.215, S D=13.776)$ and US $(M=99.705, S D=1.031)$ networks supports a more 


\section{AUDIENCE BEHAVIOR IN CHINA AND THE U.S.}

centralized and less dense Chinese network, $t(62)=-43.63, p<.0001$ (two-tailed). ${ }^{2}$ To clarify, a higher centralization score $(43.77 \%$ for the Chinese network vs. $0.30 \%$ for the US network) results from greater variability in centrality scores, with some outlets receiving a disproportionate share of audience attention. This analysis demonstrates that the observed differences are statistically significant, and offers further support for the first two hypotheses. ${ }^{3}$

Moving to the subgroup level, we get a more complex picture of the two markets. There are altogether 16 cliques identified in the Chinese market, and only four in the U.S. market (see Tables $1 \& 2$ ). Only 21 of the 62 channels appeared in the 16 Chinese cliques (clustering on the left side of the network). It is worth noting that major CCTV channels (clustering on the right side) as well as the provincial channels with larger audience reach are excluded from the cliques. A plausible explanation for this is that while these strong market contenders are present in most viewers' overall repertoires (i.e., they exist in the core), any given audience member of these channels has a relatively small repertoire. Therefore, there are less ties originating from the core channels to other channels to form closely-knit cliques on the periphery. On the other hand, the 16 cliques, similar in size and with many channels in common (see Table 1), form a general peripheral pattern of audience flow, which is distinct from that of the market "core" consisting of the channels with greater reach. These results suggest that the typical Chinese television viewer, while likely spending some time viewing popular channels in the core, also has a rather well defined channel repertoire consisting of a few channels with high levels of overlap. 


\section{AUDIENCE BEHAVIOR IN CHINA AND THE U.S.}

As for the U.S. market, the analysis only identified four cliques and there is a great deal of overlap among them. Table 2 shows that all but 11 of the 98 channels were included in all four cliques. While the four cliques demonstrate co-membership, consistent with the overall high level of overlap in the network, they do exhibit some minor distinguishing features that seem to center around language (Table 2). Cliques 2 and 4 include all ten available Spanish-language channels and none of the "Big 3" networks (ABC, CBS, NBC), although FOX is included in both. In addition, Clique 4 does not include several cable television channels (Comedy Central, AMC, CMT, and Hallmark). This could indicate a language barrier for some of the audience members in these two subgroups. Cliques 1 and 3 are very similar to each other, but different from 2 and 4. They include almost all available channels, except several of the Spanish-language channels. Moreover, Clique 1 does not include CBS, but does include Galavisión (a Spanish-language channel), while 3 includes all major networks, but not Galavisión and several other Spanish-language channels. Despite these minor differences, the general pattern of co-membership is consistent with the network level measures, again indicating diversity in unity, or consistent fragmentation in the viewing patterns of all individuals.

The results offer support for the third hypothesis. The Chinese market displays a Core-Periphery pattern, while the U.S. market is best characterized by the Pluralism pattern. However, this result does not mean that the Chinese market is more advanced than the U.S. market in the fragmentation process as McQuail's linear model speculates. Instead, the disparate patterns are a result of a combination of unique socio-economic factors in the two television markets. The finding indicates that fragmentation, as an 


\section{AUDIENCE BEHAVIOR IN CHINA AND THE U.S.}

empirical phenomenon, needs to be understood in light of the contextual specificities of the media environment.

\section{Discussion}

Efforts to reconcile different audience research approaches have been rare in theories of media economics and audience behavior. This is due in large part to the underdeveloped mechanisms through which we observe and evaluate how these factors interact (Webster, 2011). The current study developed a network analytic approach to integrate these perspectives and explore fragmentation patterns in China and the U.S. This approach is able to provide a precise representation of market structures in relation to audience behavior.

Drawing on McQuail's (1997) descriptive model as an analytical framework, the analysis demonstrates a Core-Periphery state in the Chinese market, where the viewing patterns of a number of audience segments are quite deviant from mainstream media offerings. This result indicates that Chinese audiences' viewing choices are further diversified by alternative market offerings that are made possible by local channels. This finding reflects both the central-local dynamic and the state-market tension, which results from the rapid trend of marketization and decentralization in China's TV market. The observed pattern of market structure in terms of audience viewing choice is ultimately a manifestation of the complex contours of the Chinese state's reform efforts to release the power of the market while keeping in line with its political approach to media and communication.

It is worth noting that the structural decentralization, as reflected in the observed core-periphery pattern in China's national TV market, does not necessarily lead to 


\section{AUDIENCE BEHAVIOR IN CHINA AND THE U.S.}

diverse cultural experiences in a marketplace of ideas. While market mechanisms have played an increasingly important role so that audience choice and market structure become mutually influential in the long run (Yuan \& Ksiazek, 2011), the question remains whether popular entertainment by audience choice enabled by the selective adoption of market policies provides a valid alternative to the ideological predicaments China faces today (Zhao, 2008).

Meanwhile, the U.S. market is consistent with the Pluralism model, where audiences exhibit "diversity in unity." We find high levels of overlap across the entire marketplace, suggesting that viewing patterns are consistent in their diversity, to the point of shared mediated experiences. Thus, while the Unitary model—characteristic of the early days of U.S. television-led to homogenous consumption as a result of limited competition, the current marketplace, while providing more diverse options, seems to still exhibit a great deal of homogeneity. While individuals certainly have different viewing patterns, in the aggregate we see a great deal of overlap across all options.

Audience fragmentation is often discussed in the context of socio-political implications, where a fragmented audience suggests a society with disparate cultural experiences. At its worst, fragmentation may lead to cultural stratification and gaps in political engagement or ideological division (Iyengar \& Hahn, 2009; Sunstein, 2007). Turow (1997) argued that fragmentation highlights a transition from "society-making media," which bring people together through shared exposure, to "segment-making media," which "encourage small slices of society to talk to themselves" (p. 3). In an ideal world, argued Turow, we would experience both social cohesion from society-making media and stronger group identities through segment-making media. 


\section{AUDIENCE BEHAVIOR IN CHINA AND THE U.S.}

The extensive patterns of audience overlap seen in Figure $1-$ supported by high density, low centralization scores, and a high degree of clique co-memberships-may begin to quell some common fears about fragmentation in the U.S. This is consistent with recent research on audience fragmentation, which finds evidence of a "massively overlapping culture," rather than one that is indicative of cultural and socio-political division (Webster \& Ksiazek, 2012, p. 51). The one exception is a small cluster of Spanish-language channels on the left side of the network visualization in Figure 1. This illustrates the findings from the clique analysis for the U.S. network, where despite the overall high levels of overlap among the cliques, there are minor differences that seem to center around language. Previous research has demonstrated the potential for audience polarization based on language, which could explain these findings (Ksiazek \& Webster, 2008).

The U.S. findings also have potential policy implications (e.g., antitrust litigation), insofar as they offer evidence against market concentration in terms of viewership patterns. Political economists often criticize the concentration of media ownership in the U.S., suggesting that consolidation will lead to less diversity in the provision of media. While these traditional conceptualizations of market diversity focus on ownership patterns as a proxy for the provision of diverse content, patterns of audience behavior offer an alternative understanding of diversity by relying on actual exposure patterns rather than assumptions about exposure based on patterns of provision. This means scholars, practitioners and regulatory bodies may have very different understandings of the marketplace depending on whether they look at ownership or viewership patterns. While critics of ownership concentration generally worry about 


\section{AUDIENCE BEHAVIOR IN CHINA AND THE U.S.}

stifling the marketplace of ideas, viewership patterns indicate audiences may be exposed to a greater diversity of ideas than ownership patterns might otherwise suggest. It seems that we should account for both provision and exposure when making claims about diversity in the media marketplace. This highlights the value in a network analytic approach that integrates media economics and audience behavior perspectives on fragmentation, by accounting for both structural (ownership; provision) and behavioral (exposure) patterns.

Despite the varying states of fragmentation in the two markets, these findings do not suggest that the fragmentation process is more advanced in the Chinese market than in the U.S. market. Instead, they simply highlight the impact of the different political economies of the two markets. The findings help make us aware of the inadequacy in the linear assumption of McQuail's descriptive model by situating the fragmentation patterns in the concrete contexts of media environments. Any predictions about the future developments of fragmentation, as this study has made clear, must be based on a careful consideration of all relevant socio-political factors.

Network analysis has the potential to do far more than simply describe the ways in which media outlets are connected in the marketplace. The location of individual media outlets and the structure of relations among media outlets in the network have important consequences for both individual media organizations and the market as a whole. For instance, a TV channel can identify its competitors or opportunities for growth by considering the specific patterns of interconnections among the channels and adjust its programming and market strategies. By acting and reacting to patterns of audience flow, TV channels, and the market as whole, gradually evolve in the long term. 


\section{AUDIENCE BEHAVIOR IN CHINA AND THE U.S.}

Though innovative, the current study is not without its limitations. To properly observe the mutual influence of market structure and audience agency, longitudinal data and analytical procedures are needed (Yuan \& Ksiazek, 2011). Moreover, the network statistics used to test the hypotheses in this study were mainly descriptive rather than inferential. Future studies may employ exponential random graph models (ERGM) to provide statistical tests of network features. These rigorous techniques will considerably strengthen scholars' ability to explore audience behavior patterns through network analysis. 


\section{AUDIENCE BEHAVIOR IN CHINA AND THE U.S.}

\section{References}

Anderson, C. (2006). The long tail: Why the future of business is selling less of more. New York: Hyperion.

Ang, I. (1991). Desperately seeking the audience. New York: Routledge.

Arsenault, A. H., \& Castells, M. (2008). The structure and dynamics of global multimedia business networks. International Journal of Communication, 2(2), 707748. doi: 10.1007/s10955-006-9267-8.

Barwise, T. P., \& Ehrenberg, A. S. C. (1988). Television and its audience. London: Sage.

Borgatti, S. P., Everett, M. G., \& Freeman, L. C. (1999). UCINET 6.0. Natick: Analytic Technologies.

Chaffee, S., \& Metzger, M. J. (2001). The end of mass communication? Mass Communication \& Society, 4, 365-379. doi: 10.1207/S15327825MCS0404_3

Chan, J. M. (2003). Administrative boundaries and media marketization. Chinese media, global contexts, 160-176.

Chan-Olmsted, S. M. (1991). A structural analysis of market competition in the US TV syndication industry, 1981-1990. The Journal of Media Economics, 4(3), 9-28. doi: 10.1080/08997769109358208

Ferguson, D. A., \& Perse, E. M. (1993). Media and audience influences on channel repertoire. Journal of Broadcasting \& Electronic Media, 37, 31-47. doi: $10.1080 / 08838159309364202$

Freeman, L. C. (1979). Centrality in social networks: Conceptual clarification. Social Networks, 1(3), 215-239.

Giddens, A. (1984). The constitution of society: Outline of the theory of structuration. 


\section{AUDIENCE BEHAVIOR IN CHINA AND THE U.S.}

Berkeley, CA: University of California Press.

Graf, J., \& Aday, S. (2008). Selective attention to online political information. Journal of Broadcasting \& Electronic Media, 52(1), 86-100. doi: 10.1080/08838150701820874

Hanneman, R. A., \& Riddle, M. (2005). Introduction to social network methods. Riverside, CA: University of California, Riverside (published in digital form at http://faculty.ucr.edu/ hanneman/).

Iyengar, S., \& Hahn, K. S. (2009). Red media, blue media: Evidence of ideological selectivity in media use. Journal of Communication, 59(1), 19-39. doi: 10.1111/j.1460-2466.2008.01402.x

Katz, E., Blumler, J. G., \& Gurevitch, M. (1974). Utilization of mass communication by the individual. In J. G. Blumler \& E. Katz (Eds.), The uses of mass communications: Current perspectives on gratifications research (pp. 19-32). Beverly Hills, CA: Sage.

Kim, S. (2010). Reconceptualizing audience fragmentation and polarization from a network analytic perspective. Paper presented at International Communication Association Annual Conference, San Francisco, CA, November.

Ksiazek, T. B. (2011). A network analytic approach to understanding cross-platform audience behavior. Journal of Media Economics, 24(4), 237-251. doi:

10.1080/08997764.2011.626985.

Ksiazek, T. B., \& Webster, J. G. (2008). Cultural proximity and audience behavior: The role of language in patterns of polarization and multicultural fluency. Journal of Broadcasting \& Electronic Media, 52(3), 485-503. doi:

$10.1080 / 08838150802205876$ 


\section{AUDIENCE BEHAVIOR IN CHINA AND THE U.S.}

Mandese, J. (2009, July 21). TV universe expands, share of channels tuned does not. Media Daily News. http://www.mediapost.com/publications/?fa=Articles.showArticle\&art_aid=1101 59.

McQuail, D. (1997). Audience analysis. Thousand Oaks, Calif.: Sage Publications. Monge, P. S., \& Contractor, N. S. (2003). Theories of communication networks. New York: Oxford University Press.

Napoli, P. M. (2003). Audience economics: Media institutions and the audience marketplace. New York: Columbia University Press.

Neuman, R. (1991). The future of mass audience. New York: Cambridge University Press.

Owen, B. M., \& Wildman, S. S. (1992). Video economics. Cambridge: Harvard University Press.

Ramstad, G. O. (1997). A model for structural analysis of the media market. The Journal of Media Economics, 10(3), 45-50. doi: 10.1207/s15327736me1003_4

Stroud, N. J. (2010). Polarization and partisan selective exposure. Journal of Communication, 60(3), 556-576. doi: 10.1111/j.1460-2466.2010.01497.x

Sunstein, C. R. (2007). Republic.com 2.0. Princeton, NJ: Princeton University Press.

Turow, J. (1997). Breaking up America: Advertisers and the new media world. Chicago: The University of Chicago Press.

Webster, J. G. (2005). Beneath the veneer of fragmentation: Television audience polarization in a multichannel world. Journal of Communication, 55(2), 366-382. doi: 10.1111/j.1460-2466.2005.tb02677.x 
29 AUDIENCE BEHAVIOR IN CHINA AND THE U.S.

Webster, J. G. (2006). Audience flow past and present: Television inheritance effects reconsidered. Journal of Broadcasting \& Electronic Media, 50(2), 323-337. doi: 10.1207/s15506878jobem5002_9

Webster, J. G. (2011). The duality of media: A structurational theory of public attention. Communication Theory, 21, 44-67. doi: 10.1111/j.1468-2885.2010.01375.x.

Webster, J.G., \& Ksiazek, T.B. (2012). The dynamics of audience fragmentation: Public attention in an age of digital media. Journal of Communication, 62(1), 39-56. doi: 10.1111/j.1460-2466.2011.01616.x.

Wirth, M. O. \& Bloch, H. (1995). Industrial organization theory and media industry analysis. The Journal of Media Economics, 8(2), 15-26. doi: 10.1207/s15327736me0802_3.

Yim, J. (2003). Audience concentration in the media: Cross-media comparisons and the introduction of the uncertainty measure. Communication Monographs, 70(2), 114-128. doi: 10.1080/0363775032000133773.

Yuan, E. J., \& Ksiazek, T. (2011). The duality of structure in China's national television market: A network analysis of audience behavior. Journal of Broadcasting \& Electronic Media, 55(2), 180-197. doi: 10.1080/08838151.2011.570825.

Yuan, E. J., \& Webster, J. G. (2006). Channel repertoires: Using peoplemeter data in Beijing. Journal of Broadcasting \& Electronic Media, 50(3), 524-536. doi: 10.1207/s15506878jobem5003_10.

Young, D.P.T. (2000). Modeling media markets: How important is market structure? Journal of Media Economics, 13(1), 27. doi: 10.1207/S15327736Me1301_3. Zhao, Y. (1998) Media, Market, and Democracy in China: Between the Party Line and the Bottom Line. Urbana: University of Illinois Press. 


\section{AUDIENCE BEHAVIOR IN CHINA AND THE U.S.}

\section{Endnotes}

${ }^{1}$ Each province in China has its own local market in which numerous other provincial channels and the municipal television services operate and compete against each other locally. These local markets take up one third of the total advertising market shares in China leaving CCTV channels and nationally available provincial satellite channels the rest. Conceivably, these local markets tend to segment audience flow between channels in the national market.

${ }^{2}$ The larger standard deviation in the centrality scores for the Chinese network supports this interpretation. In the US network, we see much less variance indicating greater equality in centrality scores across all nodes. This analysis also sheds light on the density comparisons. The mean scores are computed from normalized centrality scores, representing the percentage of possible links that are present for each given node. The extremely high mean value for the US network is consistent with the high overall density score, while the lower mean value is consistent with a lower density score in the Chinese network.

${ }^{3}$ This is not a conventional t-test as the measures are not independent - networks by definition are dependent. To clarify, the mean centrality scores are compared to an empirical sampling distribution created with 10,000 random permutations of the network. The magnitude of the test statistic, conservative significance level, and the consistency with the differences in centralization and density scores suggests that we can accept the difference as significant, albeit with some reservations. 


\section{AUDIENCE BEHAVIOR IN CHINA AND THE U.S.}

Figure 1

The Networks of China and U.S.
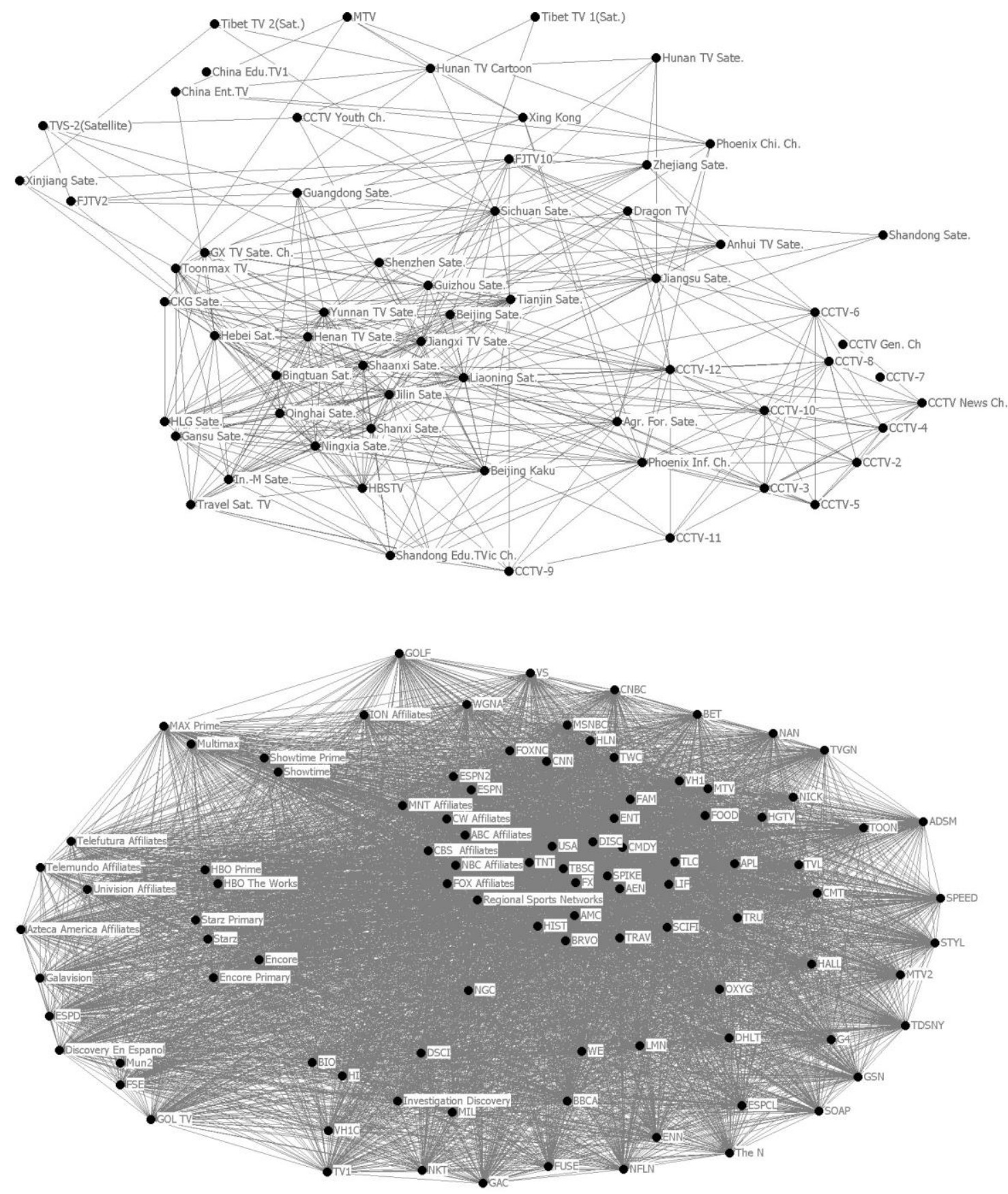


\section{AUDIENCE BEHAVIOR IN CHINA AND THE U.S.}

Table 1

Clique membership in China (Channels ranked by their Reach) ${ }^{1}$

\begin{tabular}{|l|c|c|c|c|c|c|c|c|c|c|c|c|c|c|c|c|}
\hline & 1 & 2 & 3 & 4 & 5 & 6 & 7 & 8 & 9 & 10 & 11 & 12 & 13 & 14 & 15 & 16 \\
\hline Beijing Sate. & & & & & + & & & & & & & & & & & \\
\hline CKG Sate. & & & & & & + & + & & & & & & & & & \\
\hline Tianjin Sate. & + & + & + & + & + & + & + & + & + & + & + & + & + & & & \\
\hline Jiangxi Sate. & + & + & + & + & + & + & + & & & & & & & & & + \\
\hline Liaoning Sat. & + & + & + & + & + & + & + & + & + & + & + & + & + & & & \\
\hline Henan Sate. & + & + & & & & + & + & + & + & & & & & & & \\
\hline HLG Sate. & & + & + & & + & + & & & + & + & & & & & & \\
\hline Yunnan Sate. & + & + & + & + & + & + & + & + & + & + & + & & & + & & + \\
\hline Jilin Sate. & + & + & + & + & + & + & + & + & + & + & + & + & + & + & + & + \\
\hline HBSTV & + & + & + & + & & & & + & + & + & + & & & + & & + \\
\hline Hebei Sat. & & + & + & + & + & + & + & + & + & + & + & + & + & + & + & + \\
\hline Shaanxi Sate. & + & + & + & + & + & + & + & + & + & + & + & & & & & \\
\hline Shanxi Sate. & + & + & + & + & + & & & + & + & + & + & + & + & + & + & + \\
\hline Travel Sate. & & & & & & & & & & & & + & + & & + & \\
\hline InnerM Sate. & + & + & + & + & & & & + & + & + & + & + & + & + & + & + \\
\hline Qinghai Sate. & + & + & + & + & + & & & + & + & + & + & + & + & + & + & + \\
\hline Beijing Cartn & & & + & + & + & & & & & + & + & & + & & & \\
\hline Gansu Sate. & + & & & + & & & & + & & & + & + & + & + & + & + \\
\hline Ningxia Sate. & & & & & & & & + & + & + & + & + & + & + & + & \\
\hline Toonmax TV & & & & & & & & & & & & & & + & + & + \\
\hline Btuan Sate. & + & & & & & & + & + & & & & + & & + & + & + \\
\hline
\end{tabular}

${ }^{1}$ Table 1 does not include the following channels that did not appear in any of the sixteen cliques: CCTV Gen, CCTV-6, CCTV-3, CCTV News, CCTV-4, CCTV-7, Hunan Sate., CCTV-8, Zhjiang Sate., CCTV-2, CCTV-10, Jiangsu Sate., Shdong Sate., CCTV-5, Anhui Sate., Dragon TV, CCTV Youth, Sichuan Sate., CCTV-12, Gdong Sate., Gzhou Sate., Shzhen Sate., FjianTV2, Gxi Sate., CCTV-11, China Edu. 1, Tibet 2 Sate., CCTV Music , Xinjiang Sate., Shdong Edu., CCTV-9, Hunan Cartn, Phoenix Chn., FJian 10, Xing Kong, Phoenix Inf. , Tibet 1 Sate., China Ent. , Agr. Sate., TVS-2 Sate., MTV. 


\section{AUDIENCE BEHAVIOR IN CHINA AND THE U.S.}

Table 2

Clique membership in U.S. (Channels ranked by their Reach $)^{2}$

\begin{tabular}{|r|c|c|c|c|}
\hline & 1 & 2 & 3 & 4 \\
\hline CBS Affiliates & & & + & \\
\hline NBC Affiliates & + & & + & \\
\hline ABC Affiliates & + & & + & \\
\hline Comedy Central & + & + & + & \\
\hline AMC & + & + & + & \\
\hline CMT & + & + & + & \\
\hline Hallmark & + & + & + & + \\
\hline Galavisión & + & + & & + \\
\hline ESPN Deportes & & + & & + \\
\hline Discovery En Español & & & & + \\
\hline GOL TV & & + & & \\
\hline
\end{tabular}

${ }^{2}$ Table 2 does not include the following channels that appeared in all of the four cliques: FOX Affiliates, TBS, TNT, CW Affiliates, USA, Regional Sports Networks, FX, DISC, SPIKE, MNT Affiliates, FAM, HIST, ENT, TLC, ESPN, LIF, AEN, NICK, ESPN2, SCIFI, MTV, FOOD, APL, CNN, TWC, BRVO, TRAV, VH1, FOXNC, HGTV, TOON, HLN, TRU, TVL, MSNBC, NAN, WGNA, OXYG, BET, NGC, CNBC, ION Affiliates, TVGN, VS, HBO The Works, LMN, ADSM, WE, Encore, DHLT, Univisión Affiliates, HBO Prime, MTV2, TDSNY, SPEED, G4, STYL, DSCI, GOLF, BBCA, Encore Primary, ENN, MIL, ESPCL, Starz, HI, GSN, BIO, Investigation Discovery, Telemundo Affiliates, Telefutura Affiliates, The N, NKT, SOAP, Showtime, Starz Primary, FUSE, NFLN, VH1C, Multimax, GAC, Showtime Prime, MAX Prime, TV1, Azteca América Affiliates, Mun2, Fox Sports Español (FSE). 